\title{
Interview Dr. Johann Füller, Hyve AG
}

\section{Interview Question}

Your company is well-known for designing among others innovation contests. Most recently you have started to experiment with different universities and Fraunhofer MOEZ to design innovation contests for the higher Education sector. Are there particular characteristics one needs to consider in this context? Why should higher education institutions be interested in integrating such a tool in their curriculum?

\section{Author: Dr. Johann Füller, Hyve AG}

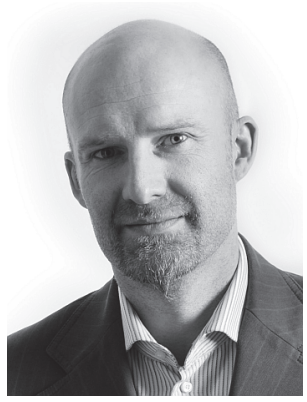

Yes, definitely: until now, students have been considered more or less as passive recipients of content and knowledge. Teaching was done from top to bottom. It was the professors and research scholars who designed the curriculum, created a syllabus and prepared the classes. Engaging students in simulations, role plays, and case studies was among the most active forms of participation. However, students rarely became active co-creators of their lecturers, co-designing the syllabus and co-creating the content of lectures. But, active engagement is actually the logical consequence of empowered users (students), available web 2.0 and social media technologies, as well as the potential of crowdsourcing, for example observed in the field of innovation.

In some areas more open and participative approaches already exist. Open Courseway and eLearning are good examples and may also be considered as forerunners for the idea of Open University/Open School. Only a few years ago, research findings, study results, and dissertations were only accessible for teachers, academics and enrolled students. Today at least virtual doors are swung up.

The Open University/Open School concept presents an entirely new and groundbreaking mindset, that aims to let researchers, teaching-staff, students and administration clerks become active contributors to the university. Similar to the concepts of Open Innovation and Open Government the focus lies on enabling student's creativity within an interactive, community driven and at the same time competitive environment.

For instance, lectures can benefit from this potential, being enriched through the content, collaboratively designed and prepared by students. Or, why not considering the creativity and user experience of students, teaching-staff, and administration clerks when planning, designing, and realizing a new canteen, sports area, or cultural programs? By being involved, participants take over responsibility, and become a guarantor for success. Why not use open innovation to let students co-create the curriculum? Students could select or suggest teaching staff, contents of teaching and the curriculum; actively take part in decision processes. One could imagine actively co-teached lessons with lectures, teamwork or the development of business-plans - not only during the lesson, but put on virtual platforms for discussion and open exchange. (With the advantage of enabling and sensitizing students not to only focus on academic, but also economic topics).Then also peer-to-peer 
reviews are conceivable. Students could support each other by grading each other, by publishing theses and doing evaluations for lessons.

While universities are exactly the place where this revolution should happen, it sometimes seems even more difficult to realize than in a corporate environment. Decisions need to be made in large steering boards and panels. Often, a majority is needed, which is not easy to achieve by a variety of opinions and different backgrounds. Further, there may be no obvious need to change.

Why should higher education institutions be interested in integrating such a tool in their curriculum?

Many benefits arise from a more open and collaborative approach. The most obvious one is that students may benefit from a more interactive education. Learning becomes easier and more efficient. Through additional input from the crowd, the content quality may also rise. However, the most important criteria may be that students themselves have the opportunity of taking responsibility and learn how to realize and apply their knowledge.

Further, an open university approach makes all protagonists gather around the table (respectively in a virtual space) and creates a common understanding and mutual respect. The access to a huge source of ideas provides an enormous potential to improve the learning conditions, optimize the administration procedure and create an inspiring university life.

Johann Füller is CEO and co-founder of HYVE AG, Munich, and a senior lecturer at the Department of Strategic Management, Marketing and Tourism at the University of Innsbruck. 